\title{
Indifference as a subversive strategy
}

\section{Leonhard Emmerling}

The more total society becomes, the more completely it contracts to a unanimous system, and all the more do the artworks in which this experience is sedimented become the other of this society. ... Because the spell of external reality over its subjects and their reactions has become absolute, the artwork can only oppose this spell by assimilating itself to it. ... This shabby, damaged world of images is the negative imprint of the administered world... Just as art cannot be, and never was, a language of pure feeling, nor a language of affirmation of the soul, neither is it for art to pursue the results of ordinary knowledge, as for instance in the form of social documentaries that are to function as down payments on empirical research yet to be done. The space between discursive barbarism and poetic euphemism that remains to artworks is scarcely larger than the point of indifference into which Beckett burrowed (Adorno, 1997: 31f).

Adorno's Aesthetic Theory, published in 1970, one year after his death, begins with the statement: "It is self-evident that nothing concerning art is self-evident anymore" (1). Beyond that, his often meandering writing is motivated by the question, "whether art is still possible"(1). This question results not only from the shock that Auschwitz caused, and which provoked the often quoted and often misunderstood sentence - to write poetry after Auschwitz would be barbarian ${ }^{1}$ - but it is also aimed at a characteristic of the work of art itself, resulting in an intrinsic and indissoluble ambivalence. Adorno reveals this ambivalence by the use of mutually complementary notions.

Autonomy and heteronomy may be seen as the configuration on which others are based, with both spheres intricately and dialectically related. The work of art aims at autonomy; or, its status in the post-feudalistic world is dictated by the autonomy of the artist from commissioners, and the limitations of social institutions like the church or the court. The artist is free to escape the demands of society by withdrawing into his own subjectivity. However, the autonomy Adorno speaks of is the autonomy of the work of art from the empirical world. The empirical world is to be considered as the same as the sphere of heteronomy, in which no other law than that of exchange is valid. Thus, another pair can be added to the autonomy/heteronomy configuration: that of "being-for-others" (everything is subject to the law of exchange), and of "being-for-itself" (the work of art).

As the autonomy of the work of art guarantees its utopian potential, ${ }^{2}$ it tends, exactly for that reason, towards an affirmation of the existing conditions, be it even involuntarily. ${ }^{3}$ As the autonomous work of art constitutes itself by follow-
I. "Cultural criticism finds itself faced with the final stage of the dialectic of culture and barbarism. To write poetry after Auschwitz is barbaric, and this corrodes even the knowledge of why it has become impossible to write poetry today". Adorno, Kulturkritik I, quoted in Martin, (2006)

2. "By emphatically separating themselves from the empirical world, their other, they bear witness that that world itself should be other than it is; they are the unconscious schemata of that world's transformation" Adorno, (1997: 177).

3. "Artworks detach themselves from the empirical world and bring forth another world, one opposed to the empirical world as if this other world too were an autonomous entity. Thus, however tragic they appear, artworks tend a priori toward affirmation" (I). 
ing exclusively its own "law of form" (Formgesetz), and so opposes any need to be useful, it is opposed to the empirical world. It is for itself instead of following social standards. "Art's asociality is the determinate negation of a determinate society"(226). This asociality, however, is also the reason for its ineffectiveness: "The society at which it shudders is left in the distance, undisturbed"(226). "Neutralization is the social price of aesthetic autonomy" (228).

Thus, every work of art is characterized by an indissoluble ambivalence. Its autonomy does not erase its character as a "fait social", and even if it is, as far as possible, removed from the "the crudely empirical" (203), it will not lose its double character as "being socially determined in its autonomy and at the same time social" (210). The aporia, to which the work of art is subjected, is not only to be found in this double character, but is more deeply constituted by the aporia of what Adorno calls the "law of form". On the one hand, this guarantees the distance of the work of art from the empirical, its being-for-itself, its autonomy and its utopian potential; but, on the other hand, the law of form itself is not free from the quality of violence. The process of submitting diverse elements to the dictates of unity and purity is modelled on the principle of heteronomy, which Adorno describes as the submission of the plurality of life to a totalitarian unity. For this, all beauty (as the purity in which the law of form is realized) has an affinity to death, in which all diversity and divergence expires (52). However, at the same time, Adorno describes the force that constitutes the work of art as a violence that respects that which it matches:

"It is through this idea that art is related to peace. Without perspective on peace, art would be as untrue as when it anticipates reconciliation. Beauty in art is the semblance of the truly peaceful. It is this toward which even the repressive violence of form tends in its unification of hostile and divergent elements" (258).

The restlessness of the dialectic process, which becomes evident here and finally threatens to end in absolute negativity, rarely comes to a standstill in Adorno's writings. He seems to undermine every positive idea of art. For that reason, it is not surprising that he writes (using Beckett again) that every work of art wants to return to silence, because it is intertwined with what he calls the universal context of guilt. And, where it does not atone for its guilt, the work of art would be nothing but a desecration of silence (134).

The absolute negativity of Adorno's theory leaves almost no way out. But there are some key notions in his theory which offer a more positive perspective. Apart from the notion of shock, and an often surprisingly positive idea about nature's beauty (das Naturschöne), it is particularly the notion of reconciliation which infuses the whole Aesthetic Theory and leads to ever new movements of thought. Questioned, doubted and reconsidered again and again, its central role and its importance regarding the work of art's potential for humankind is never undermined.

The way in which the work of art could be a pre-appearance of reconciliation unfolds in the light of the notion of "correct consciousness", which is itself dialectically folded. "..., ever since freedom emerged as a potential, correct consciousness has meant the most progressive consciousness of antagonisms on the horizon of their possible reconciliation" (191). First, this means that correct consciousness is 
historically determined and not absolute and invariant; it is not an un-historic or super-historic knowledge about the "real" character of things. Secondly, it, too, is characterised as a negativum, as the consciousness of antagonisms and not as the sum total of positive knowledge or convictions, all of which, for Adorno, are under suspicion of being ideological. Thirdly, correct consciousness unfolds on the horizon of reconciliation, as the unredeemed promise of the potential of freedom previously mentioned. Reconciliation in the work of art, therefore, happens in the form of a principal failure: "That is the melancholy of art. It achieves an unreal reconciliation at the price of real reconciliation. All that art can do is grieve for the sacrifice it makes, which, in its powerlessness, art itself is" (52). Through the irreconcilable renunciation of the semblance of reconciliation, art holds fast to the promise of reconciliation in the midst of the unreconciled ..." (33).

Adorno's ambivalent notion of reconciliation, which essentially constitutes the utopian potential of the work of art (and for which autonomy is an indispensable pre-condition), is related to his insistence on the character of the work of art as semblance. If the work of art is untruthful, insofar as it stages reconciliation as realisable, and if its truth is precisely that, in renouncing reconciliation, as a symptom of suffering and disruption, it still recollects the possibility of reconciliation negatively, then, in a world in which infatuation, as the counterpart of real alienation has become total, it stages the semblance of its being-for-itself as the mask of truth (p. 227). What appears, but is not, promises to become by appearing. "The constellation of the existing and non-existing is the utopic figure of art" (233).

\section{2}

The "unanimous system" Adorno speaks about is, today, not that of the administered world, but that of the globalized world. The mechanisms of this world follow exclusively the demands of quantification (Jameson, 1981). As long as a value can be quantified, i.e., can be transformed into an economic value, it is an object of interest. If it cannot be transformed into an economic value, it is completely ignored.

Capitalism has the wonderful nature of complete permissivity; there are no values to be fought against, because it soaks them all up. Capitalism does not attack values, nor does it destroy them; it simply incorporates and assimilates them. They live on inside capitalism, untouched, completely neutralized, as long as they do not resist its tendency to quantification. I am not sure whether there are any values that can resist.

Since World War II, two artists, more than any others, at least from a European perspective, have changed the idea of the work of art: Joseph Beuys and Andy Warhol. While Beuys' obvious political activism leaves no question regarding his critical attitude, Warhol is often discredited as a cynic, unable to develop a deeper interest in people or social issues. My question, here, is whether his strategy of indifference, and affirmation, of a society which, since capitalistic, uses values only for a humanist masking of its real indifference towards values, might be a riddle; one which is not so easily unravelled by simply resorting to the bourgeois and snobbish position that the work of art should provide us with 
that non-quantifiable surplus we are missing, painfully, in our economically determined world.

The character of indifference is to be found in Warhol at the level of his chosen medium, and at the level of semantics and iconography. The silk print, which Warhol for decades preferred to painting, comes from the profane area of advertising (Warhol began his career as a graphic designer), and is, from its origins, opposed to the valorised area of the "arts" (Groys, 1992). Its use testifies to Warhol's indifference as regards the category "art", as the principle of the one-off was given up for the principle of unlimited reproducibility, even though he produced limited editions. To distinguish a silk print reproduction of a silk print, from a silk print might be quite difficult, and borders on the imbecile; in the end, the certificate, or the signature, decides whether the print sells for five dollars in the next poster shop, or for a fortune at Sotheby's.

However, even if, following Boris Groys, we would like to read Warhol's strategy as a valorisation of the banal, it is not completely clear whether Warhol himself differentiated between the banal and the non-banal. His often quoted sentence, "All is pretty", is one of his manoeuvres to neutralize the traditional antagonisms of High and Low. The work itself does not offer any evidence that he appreciated images of cows, flowers, scissors or dollar notes less than images of Goethe, or of Leonardo's Last Supper. Instead of calling this a valorisation of the banal, it would probably make more sense to call it the elimination of the idea of "value" itself. The virtually endless reproducibility of the silk print has its analogue in the repetition of the motive, which can be understood as a negation of the idea of the image. Instead of an elaborate definition of the image, there is the motive's diffusion all over the surface, an All Over without centre, a radical equalization; instead of concentration, a tiring, if not boring, repetition of the same. And it is only logical that Warhol used this equalization for images of soup cans, porn scenes or Vesuvius, as well as for depictions of Marilyn Monroe, Mao Tsetung, James Dean or suicides jumping from sky scrapers (Feldman \& Schellmann, 1989).

Another famous sentence by Warhol states that everybody will be famous for 15 minutes. This sentence is nothing but an oxymoron: to be famous for 15 minutes means not to be famous at all. The idea of celebrity simply loses its meaning; nevertheless this phrase exactly meets our talk-show reality. And it meets, in its paradoxality, exactly the neutralization of value and meaning that is driven by capitalism. The icon of this paradoxality is Warhol's self-portrait, with the silver hair wig and camouflage patterns. This self-portrait can be understood as the culmination of his strategy to establish himself as a brand, and to disappear as a person. To the extent that Warhol established the brand Warhol - his face, his wig - the person who wore that wig vanished as a replaceable quantity. In the end, the category of individuality is eliminated by the system's unanimousity and complete indifference.

The imbecility, in distinguishing a silk printed reproduction of a silk print by Warhol, from a silk print by Warhol, is the imbecility of a system that tries to camouflage the actual worthlessness of any non-economic idea of "value" behind the smoke screen of culture; which is nothing but the nice and intellectual decoration of the actual system, skeletonized to quantifiable values. This imbecility unfolds exactly here: indifferent to the semantic, or symbolic, "value" of the image, the 
art user stares at the certificate or signature which testifies the authorship of the artist. But the surplus here is not the aura of the unique work of art, it is the aura of the fetishlike status symbol.

Warhol's productivity was enormous. The capitalistic principle of division of work in the factory facilitated an output comparable to that of a small-scale company. The market was run. It did not matter whether he delivered images of race riots, car crashes, electric chairs, fellatio, drag queens, Sigmund Freud or Queen Elizabeth, as it does not matter, from an economic point of view, if I sell higher valorised products ("good literature") or lower valorised products (porn booklets). The market swallowed everything, because it could be transformed into money. Warhol's perfect adaptation to the capitalistic mechanisms leaves no space for any euphorical estimation of "art"; it eliminates any category, perhaps even the idea of a distinction between categories.

Warhol's cruelty consisted of his strategy of duplicating the mechanisms of capitalism in a kind of mimicry. Whoever wanted to be portrayed by him was trapped by the logic of elimination of any idea of value. To be portrayed by him amounted to a humiliation, because, in the whole body of his work, the portrait had lost the privileged position it had once had in the history of art. The point, here, is that Warhol used the double faced character of the capitalistic system, and depicted it. By refusing any kind of statement, and by forcing the fetishisation of the Warhol brand, he delivered a perfect picture of the capitalistic system. Whoever bought or commissioned a work by Warhol needed to be asked if she or he were still sane. And this is the question Warhol asked of this society. In a perfidious way he testified to what Adorno had already declared: "Culture is refuse" (Adorno, 1997: 310).

\section{References}

Adorno, T. W. (1997). Aesthetic Theory (R. Hullot-Kentor, Trans.). London: Athlone Press.

Feldman, S. F., \& Schellmann, J. (1989). Andy Warhol Prints. A Catalogue Raisoné. New York: Distributed Art Publications.

Groys, B. (1992). Über das Neue. München: Fischer.

Jameson, F. (1981). The Political Unconscious. Cambridge: Cornell University Press.

Martin, E. (2006). Re-reading Adorno: The 'after-Auschwitz' Aporia. Retrieved 3 July, 2006, from http://forum.llc.ed.ac.uk/issue2/martin.html 